\title{
Articles
}

\section{Adding Grammar in a Communicatively Based ESL Program for Children: Theory in Practice}

\section{Rebecca L. Herman and Beverly Olson Flanigan}

In an effort to improve the quality of young students' second language production, classroom teachers regularly search for more efficient ways to address grammatical form under the time pressures of a content-based school curriculum. If self-correction can be increased through "consciousness raising" (Rutherford $\mathcal{E}$ Sharwood Smith, 1985), then learners would seem to benefit from form-focused instruction. For the present study, 11 elementary school students aged 7-14 were pretested and then given daily formal instruction for two weeks in the use of past tense and plural noun forms in an otherwise content-based and communicatively oriented ESL program, after which they were posttested twice. A significant difference was found between this instructed group and a matched control group receiving no instruction in the successful detection and correction of noun plural forms, but not in a similar test of past tense forms. Furthermore, the instructed group continued to perform well on noun plurals after one month of no focused instruction, suggesting that attention to form had some lasting beneficial effect. Possible reasons for the differential results are discussed.

\section{Introduction}

Adult second language learners in a classroom setting usually want, and presumably benefit from, explicit grammar instruction (Fotos, 1994; Long, 1983; Oladejo, 1993; White, 1987). Children, on the other hand, have been thought to need less explicit instruction on form, if any at all (Celce-Murcia, 1991; VanPatten, 1987). However, a more moderate, and traditional, view assumes that some attention to form is beneficial and even necessary to prevent early fossilization of undesired forms, even in children (Lightbown, 1991; Lightbown \& Spada, 1990; Long, 1991; Schachter, 1991; Van Baalen, 1983).

Among recent attempts to justify teaching grammar are the "consciousness raising" proposals of Rutherford and Sharwood Smith (1985; compare also Schmidt, 1990; Sharwood Smith, 1991, among others) and the various "language awareness" themes sounded in James and Garrett (1991). Underlying these proposals is the theory that learners can be helped to increase 
their own awareness of both explicit (external) input and implicit (innate) language knowledge, and that this metalinguistic awareness would presumably improve the rate of learning if it could be sustained throughout successive interlanguage stages (compare Bialystok, 1979, 1982; Fotos, 1994; Green \& Hecht, 1992; McLaughlin, 1990).

This study was designed to test whether adding explicit formal grammar instruction for two weeks in an otherwise communicative syllabus that emphasized content-based input and oral interaction would benefit elementary school learners of English as a second language. Three research questions were posed. First, would a group receiving instruction on selected grammatical forms show significant improvement in test scores after a two-week instruction period? Second, would the instructed group show a sustained level of performance on those forms on a posttest after one month without review? And third, would a control group not explicitly instructed in grammar show significantly less improvement on those forms during the same six-week period?

A brief summary of the theoretical bases for such a study follows, after which the research study is explained. Although it is seen that improvement was sustained over time on one of the forms chosen for attention but not on the other, the discussion addresses the larger argument of whether increased attention to form is desirable for students at the elementary school level.

\section{Background}

There are many approaches to assisting learners to acquire correct forms in a new language. Some teachers rely on positive evidence alone by providing learners with correct examples of the target language, an approach presumed to correspond to first language (L1) learning. Reasoning that the success rate for learning one's mother tongue is $100 \%$, some theorists support using positive evidence alone. Krashen (1992), for example, believes that reading in quantity should provide sufficient comprehensible input, dismissing explicit grammar instruction as "peripheral and fragile" at best. However, most applied linguists, teachers, and indeed learners believe that second language (L2) learning is not like the first. The low success rate of L2 learners is one major indicator of the difference (Bley-Vroman, 1988; Schachter, 1991). An often-cited study by Ervin-Tripp (1974) on children aged 4-9 in a French submersion program in Geneva concluded that the development of comprehension of syntax followed the L1 order. However, sequence, and even age, are not the only relevant criteria for measuring acquisition. Errors can be difficult or impossible to eradicate in L2 learners, even in children who have had several years of such immersion in a foreign language (Harley \& Swain, 1984). A study by Trahey and White (1993) found that, after two weeks of "flooding" of input containing English adverbs in an ESL program for students aged 11-12 years, learners would add new forms to their inter- 
language while at the same time retaining incorrect forms. Positive input alone was not sufficient to enable those learners to supplant incorrect forms with correct forms.

Another study by Ioup (1989) showed that children aged 6-9 who were mainstreamed in American schools from the start without ESL support eventually needed to take intensive English courses at the college level before being allowed to enter a university. Again, positive evidence of natural speech in a (forced) immersion setting was apparently not adequate for learning a new language, even when those learners started using the L2 in kindergarten.

Neither have studies of the effect of providing negative evidence, either alone or combined with positive input, led to totally satisfactory results. Negative evidence, that is, explicitly calling attention to grammatical rules through instruction of formal restrictions or correction of errors (BleyVroman, 1986; Lightbown, 1991; Schachter, 1991; White, 1987), has been presumed to be unnecessary in child L1 acquisition; its value in SLA, whether with children or adults, although assumed to be of some benefit, has not been clearly demonstrated. White (1991), for example, admitted to not knowing whether instruction and testing of adverb placement in an ESL program had had the beneficial effect it appeared to have, because the students had inevitably received positive naturalistic input as well (compare also Schwartz \& Gubala-Ryzak, 1992).

Providing learners with negative input only (i.e., erroneous samples of the target language) would, of course, be unwise as a complete instructional method, but some samples of incorrect forms may serve as a focus on undesired forms and prevent them from occurring or recurring. One innovative approach is the "garden path" technique developed by Tomasello and Herron $(1988,1989$; compare also Herron, 1991). These researchers have found that when learners are given a general rule and then deliberately invited to apply the rule to an irregular base, the subsequent correction makes a greater impression than does sporadic correction of errors after they appear in learners' spontaneous performance. The negative evidence is thus the students' own product, albeit an artificially induced one. This approach was not chosen as an option in the present study, however, for obvious reasons. Despite the consistent improvement found in these adult-based studies, such an approach borders on tricking trusting children into deliberately making errors, hardly justifiable from our point of view.

Explicit teacher correction of spontaneously produced errors is, of course, a traditional classroom activity. However, Horner (1988) suggests that although correction seems to have some effect, teachers cannot, and should not, correct everything; which forms, and when, are most correctable is then the issue. More typical of recent attempts at providing feedback on errors are those that generalize a few common weaknesses and then guide learners to 
examine and correct their own output. However, even this type of correction may be too subtle to be effective. Sharwood Smith (1991) notes that such indirect consciousness raising is not always internalized or used by the students to promote their own learning unless it is combined with at least some overt correction as well.

In an effort to provide explicit, and usable, help to learners, teachers and researchers are experimenting with the amount of grammar taught, the extent to which it is focused on, and the time at which such focus is given. Some projects emphasize "input enhancement," providing an explicit grammar focus with or without error correction, perhaps for three to 10 days but varying in the intensity of instruction per day (White, Spada, Lightbown, \& Ranta, 1991). Some researchers find that instructed learners improve immediately on the first posttest, but the degree of maintenance of improvement after a few weeks varies widely (Ellis, 1984; Lightbown, Spada, \& Wallace, 1980; VanPatten, 1987; White, 1991).

The present study employed both positive and negative input enhancement. The negative evidence used was not the students' own errors, but short prepared texts in which the students were asked to locate and then correct certain types of errors. The instructional period in this literacyfocused program included an examination of positive written samples of correct usage. One long-term goal was to train students to monitor (proofread) their own writing more meticulously so that they might come to anticipate and correct their own mistakes. This last goal was difficult to investigate, however, without a longer period of observation, because of the high attrition rate of the participants and the ending of the school year.

\section{Method}

\section{Participants}

Twenty-two elementary school students in grades 2 through 8 were divided into two groups of 11 each. ${ }^{1}$ Both groups were matched for a similar range of ages (7-14), first language backgrounds ( 9 different languages), and proficiency levels (3-5 on a scale of 1-5, 5 representing native-like grammatical proficiency on the Bilingual Syntax Measure, Burt, Dulay, \& HernandezChavez, 1975). ${ }^{2}$ Their length of residence in the United States ranged from four to 21 months at the start of this study. All the children were studying ESL in a pull-out lab setting where they spent 45 minutes on independent activities and computer exercises and 45 minutes in tutorials focusing on literacy, with little overt grammar instruction. The remainder of the school day was spent in mainstream classes where $80 \%$ of the students were native speakers of English. The two eldest students, a Korean boy and a Chinese girl, each had had two years of EFL before entering the ESL program. The others were complete beginners at the time of enrollment. 
It is difficult to gauge how much exposure to English each child experienced in other settings. Even in this small university town setting, it was impossible to verify how often the children were exposed to English outside school, as some parents encouraged their children to socialize, whereas others tried to ward off all North American influences on their children. The parents were all enrolled at the local university; thus the purpose for which these families were present, compounded by their temporary status and their specific educational goals, may have influenced their attitudes. However, all parents voiced public support for the advantages to their children of learning English, at least in the school setting.

\section{Materials}

All students were first given one story text containing 24 base verbs that required inflection for past tense in context and another containing 21 nouns requiring plural marking in context; both stories were written by the program director and contained familiar content and lexicon. The participants were asked to read each story silently, locate the forms to be inflected, circle them, and then write the correct forms in the right-hand margin (see Appendix for sample test). Each story was preceded by a sample question-andanswer pair that called for the form the students were to identify, but no hint was given as to which form, past or plural, was required. The answer column for each test was not numbered so as not to set up prior expectations of the total number of errors to be detected. Students were allowed up to 40 minutes to complete each test, but most finished within 25 minutes. Tests were either separated by a half-hour break or given on consecutive days.

Two posttests were given. The first was the same as the pretest, but the second (given after four weeks of no instruction) was a slight variation on the first in the hope that students' interest, and performance, would not be unduly affected by prior familiarity with the material. However, the same verbs and nouns were tested, and even the story lines were similar. None of the participants in either group was given feedback on any of the tests, because the purpose of the study was to measure learning rather than simple memorization of test items.

The format for the tests was unusual for the children involved in the study, first because they had never been asked to detect errors in a printed text before, and second because the style of response was new to them. They were therefore given practice in the procedure on four consecutive days of half-hour practice sessions before the day of the official pretest.

\section{Procedure}

Students in both groups were taught by either the program director (and co-researcher) or one of four trained teaching assistants from the graduate program in linguistics at Ohio University; because all conducted individual 
or small-group tutorials throughout the year, no change in procedure would have been detected by the students. Absolute consistency could not be established among teachers, but those teaching the experimental group were responsible for maintaining a checklist verifying the exact date on which the targeted grammatical forms were taught. In addition to the checklist, each teacher was required to keep a daily log of the contents of each day's lesson, to which the director would respond. Daily communication in person was also maintained.

The students in the experimental, or instructed, group were given the pretest followed by explicit grammar instruction for up to 15 minutes per day over a two-week period. Because each tutorial was normally 30 minutes long, the teachers were told to spend five to 15 minutes of that period teaching a grammar lesson on both past and plural forms as a supplement to the usual content-based lesson for the day. Because some teachers needed a few days to learn to gauge their time or to accommodate to an occasional student's absence, the experimental period lasted up to 14 , rather than 10 , school days for some of the participants.

The type of instruction given to the experimental group included planned, formal presentations on plural and past forms supplemented by written examples. These were in part created by the individual teachers and in part provided by the director in an attempt to promote consistency among the various teachers of the experimental group. Text-based activities consisted of error detection and correction as well as slot-filling exercises. All teachers were urged to direct explicit attention to plural and past tense forms in these texts. Therefore, instruction included practice in correction of errors (negative evidence) and attention to correctly used forms (positive evidence).

To minimize embarrassment for the children, attention to form in the assigned written work of the experimental group was done in private, either as a written correction on the assignment or in individual consultation. The program director had also planned to give limited corrective feedback to the spontaneous oral productions of the 11 students in this group, but the younger children (ages 7-8) did not respond favorably to, and even seemed to resent, such reactive correction, so it was completely dropped with the entire group after the first two days in order to maintain consistency across participants.

The control, or noninstructed, group was given the same pretest followed by content-based communicative instruction with no unusual attention to form. Because the teachers occasionally had students from both groups in mixed settings, all teachers were alerted not to supply specific instruction on the tested forms to the control group during this period. Again, daily written logs of all lessons were kept and checked to ensure consistency of presentation and content by all the teachers for each group. 
The same test was administered again to both groups immediately after the two-week period. All participants then resumed content-based instruction, with no explicit review or unusual attention to the tested forms. After four additional weeks, a final posttest on the same forms (but in a different story) was administered to both groups. The entire six-week period coincided with the last quarter of the academic school year.

\section{Scoring}

All the tests were graded by the program director. An answer key was used, because only one answer was judged acceptable for each response. Although the students were warned that spelling would be counted, only the main inflection was evaluated for accuracy (e.g., corected was accepted). Wrong answers and missing responses were not counted. Each score reflected the number of words that had been correctly circled in the passage and copied with the correct inflection in the answer column. Irregular past tense verbs were counted correct only if the entire spelling was correct.

\section{Results}

Table 1 below gives the mean scores on the three tests of plural noun forms for both the instructed (experimental) group and the noninstructed (control) group. Table 2 provides the mean scores for both groups on past tense forms. Separate two-way ANOVA tests with repeated measures were performed on the noun scores and the past tense scores, using instruction as the betweenparticipants factor and time of test as the within-participants factor and with test scores as the dependent variable.

A $t$-test on the scores of the noun pretest determined that the two groups of children were not significantly different $(t(20)=1.08 ; p=.294)$; in other words, selection of the two groups on the basis of BSM scores was successful in obtaining homogeneity between groups. To see if any improvement occurred during the two-week instructional period, an ANOVA test was con-

\section{Table 1}

Correct Plural Noun Use in Two Learner Groups

\begin{tabular}{lccc}
\hline & Pretest & 2-wk Posttest & 6-wk Posttest \\
\hline Instructed $(n=11)$ & & & \\
$\quad$ Mean (\%) & 42.5 & 62.5 & 64.4 \\
SD & 22.5 & 20.1 & 24.4 \\
Noninstructed $(n=11)$ & & & \\
Mean (\%) & 33.8 & 39.7 & 44.5 \\
SD & 14.6 & 15.4 & 15.5 \\
\hline
\end{tabular}


ducted on the scores of the pretest and the first posttest (Time 1 and Time 2). The results showed significant main effects for instruction $(F(1,20)=4.75$; $p=.041)$ and time $(F(1,20)=17.38 ; p<.001)$. More importantly, the interaction between instruction and time was also significant $(F(1,20)=5.14 ; p=.035)$, indicating that there was improvement in the performance level of the instructed group, but not of the noninstructed group.

An ANOVA run on the noun scores of the two posttests (Time 2 and Time 3) also showed a significant main effect for instruction $(F(1,20)=7.30$; $p=.013)$. That is, the group receiving instruction in noun pluralization performed significantly better than the group receiving no instruction, indicating that grammar instruction on this feature was beneficial. However, no significant main effect for time was found $(F(1,20)=1.99 ; p=.173)$; in other words, performance levels were maintained by both groups from Time 2 to Time 3. Third, no significant interaction between instruction and time was observed $(F(1,20)=.41 ; p=.531)$. That is, the instructed group and the noninstructed group sustained their earlier patterns of behavior: the scores of the instructed group remained high and those of the noninstructed group remained low (though slightly improved) at both Time 2 and Time 3 .

Similar tests were run on the verb tense tests (see Table 2).

Initial $t$-tests for homogeneity of groups again indicated no significant difference at the outset of the study, that is, on the pretest $(t(20)=.03 ; p=.974)$. However, this time an ANOVA conducted on the difference between the pretest scores and the first posttest scores indicated no significant main effect for instruction $(F(1,20)=.60 ; p=.449)$ or for time of test $(F(1,20)=.87 ; p=.363)$, although the results were in the predicted direction; that is, the scores of the instructed group improved to some degree. The interaction between instruction and time was also not significant $(F(1,20)=2.86 ; p=106)$. An ANOVA run on the two posttests again showed no main effect for instruction $(F(1,20)$ $=.99 ; p=.333)$ or for time of test $(F(1,20)=.75 ; p=.397)$. The instruction by time interaction was also not significant $(F(1,20)=2.17 ; p=1.57)$. Thus instruction

Table 2

Correct Past Tense Use in Two Learner Groups

\begin{tabular}{lccc}
\hline & Pretest & 2-wk Posttest & 6-wk Posttest \\
\hline $\begin{array}{l}\text { Instructed }(n=11) \\
\quad \text { Mean (\%) }\end{array}$ & 50.8 & 63.4 & 58.5 \\
SD & 34.5 & 19.3 & 25.0 \\
Noninstructed (n=11) & & & \\
$\quad$ Mean (\%) & 50.4 & 46.7 & 49.3 \\
SD & 30.3 & 26.9 & 29.3 \\
\hline
\end{tabular}


seems not to have helped in regard to verb tense accuracy, nor was there significant change in either group from Time 2 to Time 3.

\section{Discussion}

To return to the three research questions posed, we found that (a) focused instruction on grammar appeared to be effective in the case of noun plural formation as measured immediately after the period of instruction, but it was not effective in the case of past tense formation; (b) improvement in noun pluralization was sustained to a significant degree by the instructed group as measured after four weeks of no focus on form, but no such effect occurred on past tense; and (c) the group receiving no grammar instruction improved slightly (but not significantly) on noun plurals during the six weeks of the study, but not on past tense marking.

Because of the small number of participants, the briefness of the testing period, and the mixed results obtained on the noun and verb tests, we would hesitate to conclude categorically that focused instruction in grammar is beneficial at the elementary school level. Moreover, some unavoidable aspects of the teaching procedure may have affected the results: personal and environmental distractions experienced by the children across the six-week period, inevitable inconsistencies in teaching styles and content among the five teachers in spite of training and monitoring, and possible flaws in the tests themselves.

However, the tasks given should have been manageable for all 22 participants considering that they had all been practicing similar verb forms at least twice a week at independent computer activities since they learned how to read in English. They had repeated the same drills for several months preceding the test, and all students' computer scores on 53 irregular past tense verb forms in a multiple-choice test administered earlier were nearly perfect. Admittedly, the story task was more demanding than a cloze format that tells the student exactly where the correct form should occur and gives a list of four answers to choose from. However, even though the computer practice could not be considered a correction task, the regular attention brought to such a narrow task should have theoretically induced some heightened level of awareness of the past tense (compare Fotos, 1994). This study does not indicate any such effect, or at least one that translated to another type of task.

In the light of such prior expectations, therefore, the improvement, and the sustaining of improvement, in noun plural accuracy among the instructed children cannot be ignored. A developmental theory of second language acquisition would suggest that all the children would acquire both the targeted grammatical forms in time, but the instructed group clearly outpaced the noninstructed group in noun pluralization. However, it did not do so in past tense marking, even though the same amount of time was 
devoted to that rule. If the proposed stages of grammatical acquisition have been correctly defined (compare Dulay \& Burt, 1974; Pienemann, 1986; Pienemann, Johnston, \& Bradley, 1988), it is possible that these children had not yet acquired the ability to understand and internalize the rule for past tense in English, and therefore instruction during this period probably would not have significantly helped to effect such understanding. However, because there was a trend toward improvement, although not significant, the possibility that some of the children were influenced by instruction cannot be ruled out.

The supposition that irregular past tense is acquired more easily than regular was not supported here either; unlike L1 children, who presumably pass from early acquisition of irregular forms to overgeneralizing of all verbs as regular past (Shipley, Maddox, \& Drive, 1991), these L2 learners did not exhibit this staging, unless they had already passed through it prior to our testing period; in fact, they had more errors (i.e., corrected fewer forms) in irregular verbs than in regular (see Flanigan, 1991, for earlier evidence of greater difficulty with irregular forms among a similar group of children of similar proficiency levels in the same school).

On the other hand, the children in both groups were presumably ready for noun pluralization, because both groups improved on the plural tests and sustained that improvement over time. However, the instructed group improved significantly more than the group receiving no instruction and kept up its higher level of performance over time, suggesting that focus on form in a concentrated, if not "flooded," manner enhanced the normal developmental acquisition process in a salutary way (Lightbown \& Spada, 1990; Sharwood Smith, 1991; White, 1991). Whether such instructional intervention preempted less desirable forms and thereby prevented them from fossilizing (Rutherford, 1989; Trahey \& White, 1993) is less certain, particularly because the participants were children and could be presumed to progress to high levels of proficiency in time anyway (Pienemann, 1986; but see Harley \& Swain, 1984; Ioup, 1989, for opposing evidence). But the potential benefit of grammar instruction is clearly evident in our results and would appear to support those who claim that teaching grammar is not, after all, a waste of time, even for young children (Doughty, 1991; James \& Garrett, 1991; Schmidt, 1990).

\section{Pedagogical Implications}

The patterns described above need to be addressed individually to examine whether consciousness raising might be effective for children even if the statistical results do not always support that hypothesis. The finding of significant improvement on pluralization with concomitant lack of improvement on past tense after instruction is evident in the mean scores but may have multiple explanations. Celce-Murcia (1992), in her retrospective review 
on the changing attitudes toward the role of grammar over the past 25 years, suggests both that young children are naturally more holistic in learning language than adults are, and that a grammar emphasis becomes important to the learner only when productive skills such as speaking and writing are the focus, as they were not in this correction task. In analyzing the ratio of regular to irregular errors, we found that students typically got three irregulars wrong for every two incorrect regular past tense forms. Thus the past tense form may not be perceived as having two distinctive realizations by beginning-level children, for whom the function is met by either marking. Plurals, on the other hand, are more regular; therefore, once the count-noun rule in the L2 is understood, the potential for errors is not complicated by the need for a morphological marking choice.

Another possible explanation for the fact that some learners did not improve after instruction may be tied to the cognitive stage of development of the lagging learners. In a study by Shipley, Maddox, and Drive (1991), data on irregular past tense use in the speech of 120 English L1 speakers aged 3-9 revealed that some children did not master some of the forms even by 9 years of age. We may, therefore, have been expecting some participants in the present study to focus on a type of form for which they were not yet cognitively or linguistically ready.

In addressing our second research question, we found not only less success in learning past tense forms than plurals, but even less success sustaining whatever gains were made. Some participants did, of course, improve on the first posttest as expected. In fact, there was a $12 \%$ increase in the mean experimental (instructed group) score on the first past tense posttest, reflecting an improvement even if not a significant difference between this group and the noninstructed group. But why would the instructed learners not sustain any significant knowledge of these forms over time? Students were tested on exactly the same verbs, yet many had forgotten the correct forms after four weeks. Another important issue, then, is whether the manner of presenting grammatical information can have a differential effect on learning. One study by VanPatten and Cadierno (1993), comparing three adult groups using past tense forms, indicated that the group instructed in processing and interpreting strategies achieved higher scores on three posttests than the other groups, which received either traditional instruction or none at all. These results were maintained even on a third posttest one month after the experimental instructional period. In addition, White, Spada, Lightbown, and Ranta (1991) found in a five-week follow-up test that improved use of question formation by French ESL students in grades 5-6 was sustained after a combination treatment of corrective feedback and instruction. As noted earlier, Tomasello and Herron (1988) found that employing a "garden path" approach to learning grammar forms improved the compositions of beginning level learners of French, an improvement that was sus- 
tained over the entire semester. Thus the method of giving our students in the experimental group traditional instruction without feedback may not have had the sustaining effect we had hoped for.

The third research question asked whether learners would fail to improve without specific focus on the selected forms. The results showed that some improvement took place naturally (i.e., developmentally) over the six-week period in the identification and correction of plural forms (though not of past tense) by the noninstructed group. These findings support the assumption that positive evidence in quantity is at least potentially helpful to all learners. If teachers feel they have the luxury of time to allow their students to glean what they can at their own pace, then teaching solely through a contentbased syllabus without a focus on form would appear to be justified.

\section{Conclusion}

Should elementary school ESL teachers add grammar to their communicative curriculum? Adding some explicit attention to form in a content-based curriculum remains attractive to teachers and, frequently, to older students who are accustomed to such form-focused instruction in their home countries. However, if we do choose to supplement our teaching with more form, the timing of such instruction may not be so clearly related to age. A study of 577 Southeast Asian immigrant students in grades 2-10 (Weslander \& Stephany, 1983) indicated that the length of time enrolled in such a program was the single best predictor of academic success, but that the first year of schooling was found to be the best time for making maximum progress in grammar. This suggests that timing be considered not only in the local context of a lesson (Lightbown, 1992), but also in the more global sense of long-term planning of such instruction, whether it be done through focus on form, input flooding, corrective feedback, or some other method.

Harley (1993) reviews the pitfalls of relying on either extreme, that is, of focusing on experiential teaching (communicative immersion) or on analytic approaches that might overemphasize accuracy. Assuming that some focus on accuracy is desirable, she attempts to resolve the problem by proposing four principles for incorporating a focus on form in the classroom. Using examples from programs in French immersion in elementary school by English-speaking learners, she first proposes a "compensatory salience principle" that urges analytic teaching for certain nonobvious differences between the L1 and L2 and similar undernoticed forms (compare Sharwood Smith's, 1991, "induced input salience"). The second principle, the "barrierbreaking principle," supplements the first by urging explicit reanalysis of certain forms that block students from progressing. Third, her "integration principle" states that any stage is appropriate for an analytic focus on code, as long as teachers do not overestimate students' linguistic capacity. Although Harley skirts the issue of how to determine such capacity, or readi- 
ness, she does address when to analyze certain forms through this third principle. With the fourth, the "learning task principle," Harley proposes how to incorporate analysis of code by recommending that teaching strategies be determined by the kind of learning task involved.

Such an approach supports our view that, although the primary focus in public school ESL must be on communication and content, it is also the responsibility of language teachers to prepare children for the grammatical demands of nonsheltered schooling in the second language. Indeed, students need to learn a wide variety of response patterns to better cope with the expectations of the mainstream classroom, and therefore it would be well to "focus on form" whenever possible and in any way feasible if we are to help them achieve this goal.

\section{Acknowledgments}

This article is an expanded version of a presentation given at the American Association for Applied Linguistics conference in Atlanta, Georgia on April 17, 1993. The authors wish to thank Muljani Djojomihardjo for her help on the statistical analysis, as well as the four teaching assistants at East Elementary School in Athens, Ohio who participated in the instruction and data collection reported on here.

\section{Notes}

${ }^{1}$ The data pool was limited by the number of limited-English-proficient students enrolled in the ESL pull-out program at the time of the study. Furthermore, because only those children scoring 3 or above on the Bilingual Syntax Measure and possessing functional literacy would be able to do the grammar completion tasks, the number of eligible students was further limited. Children typically stay in the program for two years; because some entered in January and others were already in their second year, the length of residence was 4-21 months at the time of the May study.

${ }^{2}$ The BSM (version I) was regularly used by the program director, together with other tests, for entry and exit purposes; her successful use of this measure over the years lent credibility to the BSM despite its well-known limitations. At the time of the study, version II was not available at the school; since then, other assessment scales have supplanted the BSM.

\section{The Authors}

Rebecca L. Herman is a doctoral student in the Department of Foreign Language Education at the University of Texas in Austin. She was the director of the ESL program at East Elementary School in Athens, Ohio at the time of the research reported on here.

Beverly Olson Flanigan is an associate professor of linguistics at Ohio University in Athens. She teaches courses in second language acquisition, TEFL methodology, and sociolinguistics and is the author of several articles on SLA in children and on bilingual education and variational English in North American First Nations reservation schools.

\section{References}

Bialystok, E. (1979). Explicit and implicit judgments of L2 grammaticality. Language Learning, 29, 81-103.

Bialystok, E. (1982). On the relationship between knowing and using linguistic forms. Applied Linguistics, 3, 181-206. 
Bley-Vroman, R. (1986). Hypothesis testing in second-language acquisition theory. Language Learning, 36, 353-376.

Bley-Vroman, R. (1988). The fundamental character of foreign language learning. In W. Rutherford \& M. Sharwood Smith (Eds.), Grammar and second language teaching: A book of readings (pp. 19-30). New York: Newbury House.

Burt, M., Dulay, H., \& Hernandez-Chavez, E. (1975). Bilingual syntax measure. New York: Harcourt Brace Jovanovich.

Celce-Murcia, M. (1991). Grammar pedagogy in second and foreign language teaching. TESOL Quarterly, 25, 459-480.

Celce-Murcia, M. (1992). Formal grammar instruction: An educator comments. TESOL Quarterly, 26, 406-409.

Doughty, C. (1991). Second language instruction does make a difference: Evidence from an empirical study of SL relativization. Studies in Second Language Acquisition, 13, 431-469.

Dulay, H., \& Burt, M. (1974). Natural sequences in child second language acquisition. Language Learning, 24, 37-53.

Ellis, R. (1984). Can syntax be taught? A study of the effects of formal instruction on the acquisition of WH questions by children. Applied Linguistics, 5, 138-155.

Ervin-Tripp, S. (1974). Is second language learning like the first? TESOL Quarterly, 8, 111-127.

Flanigan, B. (1991). Variable competence and performance in child second language acquisition. Second Language Research, 7, 220-232.

Fotos, S. (1994). Integrating grammar instruction and communicative language use through grammar consciousness-raising tasks. TESOL Quarterly, 28, 323-351.

Garrett, N. (1986). The problem with grammar: What kind can the language learner use? Modern Language Journal, 70, 133-148.

Green, P., \& Hecht, K. (1992). Implicit and explicit grammar: An empirical study. Applied Linguistics, 13, 168-184.

Harley, B. (1993). Instructional strategies and SLA in early French immersion. Studies in Second Language Acquisition, 15, 245-259.

Harley, B., \& Swain, M. (1984). The interlanguage of immersion students and its implications for second language teaching. In A. Davies, C. Criper, \& A. Howatt (Eds.), Interlanguage (pp. 291-311). Edinburgh, UK: Edinburgh University Press.

Herron, C. (1991). The garden path correction strategy in the foreign language classroom. French Review, 64, 966-977.

Horner, D. (1988). Classroom correction: Is it correct? System, 16, 213-220.

Ioup, G. (1989). Immigrant children who have failed to acquire native English. In S. Gass, C. Madden, D. Preston, \& L. Selinker (Eds.), Variation in second language acquisition: Vol. 2: Psycholinguistic issues (pp. 160-175). Philadelphia, PA: Multilingual Matters.

James, C., \& Garrett, P. (Eds.). (1991). Language awareness in the classroom. New York: Longman.

Krashen, S. (1992). Formal grammar instruction: Another educator comments. TESOL Quarterly, 26, 409-411.

Lightbown, P. (1991). Input, instruction, and feedback in second language acquisition. Second Language Research, 7 , ii-iv.

Lightbown, P. (1992). Getting quality input in the second/ foreign language classroom. In C. Kramsch \& S. McConnell-Ginet (Eds.), Text and context: Cross-disciplinary perspectives on language study (pp. 187-197). Lexington, MA: D. C. Heath.

Lightbown, P., \& Spada, N. (1990). Focus-on-form and corrective feedback in communicative language teaching: Effects on second language learning. Studies in Second Language Acquisition, 12, 429-448.

Lightbown, P., Spada, N., \& Wallace, R. (1980). Some effects of instruction on child and adolescent ESL learners. In R. Scarcella \& S. Krashen (Eds.), Research in second language acquisition (pp. 162-172). Rowley, MA: Newbury House. 
Long, M. (1983). Does second language instruction make a difference? A review of research. TESOL Quarterly, 17, 359-382.

Long, M. (1991). Focus on form: A design feature in language teaching methodology. In K. de Bot, R. Ginsberg, \& C. Kramsch (Eds.), Foreign language research in cross-cultural perspective (pp. 39-52). Philadelphia, PA: John Benjamins.

McLaughlin, B. (1990). "Conscious" vs. "unconscious" learning. TESOL Quarterly, 24, 617-634.

Oladejo, J. (1993). Error correction in ESL: Learners' preferences. TESL Canada Journal, 10, 71-89.

Pienemann, M. (1986). Psychological constraints on the teachability of languages. In C.W. Pfaff (Ed.), First and second language acquisition processes (pp. 103-116). Rowley, MA: Newbury House.

Pienemann, M., Johnston, M., \& Brindley, G. (1988). Constructing an acquisition-based procedure for second language assessment. Studies in Second Language Acquisition, 10, 217-243.

Rutherford, W. (1989). Preemption and the learning of L2 grammar. Studies in Second Language Acquisition, 11, 441-458.

Rutherford, W., \& Sharwood Smith, M. (1985). Consciousness raising and universal grammar. Applied Linguistics, 6, 274-282.

Schachter, J. (1991). Corrective feedback in historical perspective. Second Language Research, 7 , 89-102.

Schmidt, R. (1990). The role of consciousness in second language learning. Applied Linguistics, 11, 129-158.

Schwartz, B., \& Gubala-Ryzak, M. (1992). Learnability and grammar reorganization in L2A: Against negative evidence causing the unlearning of verb movement. Second Language Research, 8, 1-38.

Sharwood Smith, M. (1991). Speaking to many minds: On the relevance of different types of language information. Second Language Research, 7, 118-132.

Shipley, K., Maddox, M., \& Drive, J. (1991). Children's development of irregular past tense verb forms. Language, Speech, and Hearing Services in Schools, 22, 115-122.

Tomasello, M., \& Herron, C. (1988). Down the garden path: Inducing and correcting overgeneralization errors in the foreign language classroom. Applied Psycholinguistics, 9 , 237-246.

Tomasello, M., \& Herron, C. (1989). Feedback for language transfer errors: The garden path technique. Studies in Second Language Acquisition, 11, 385-395.

Trahey, M., \& White, L. (1993). Positive evidence and preemption in the second language classroom. Studies in Second Language Acquisition, 15, 181-204.

Van Baalan, T. (1983). Giving learners rules: A study into the effect of grammatical instruction with varying degrees of explicitness. Interlanguage Studies Bulletin, 7, 71-100.

VanPatten, B. (1987). On babies and bathwater: Input in foreign language learning. Modern Language Journal, $71,156-164$.

VanPatten, B., \& Cadierno, T. (1993). Input processing and second language acquisition: A role for instruction. Modern Language Journal, 77, 45-57.

Weslander, D., \& Stephany, G. (1983). Evaluation of an English as a second language program for Southeast Asian students. TESOL Quarterly, 17, 473-480.

White, L. (1987). Against comprehensible input: The input hypothesis and the development of L2 competence. Applied Linguistics, 8, 95-110.

White, L. (1991). Adverb placement in second language acquisition: Some effects of positive and negative evidence in the classroom. Second Language Research, 7, 133-161.

White, L., Spada, N., Lightbown, P., \& Ranta, L. (1991). Input enhancement and L2 question formation. Applied Linguistics, 12, 416-432. 


\section{Appendix}

Sample Format for the Three Tests:

2-week Posttest on Noun Plurals

Directions: Circle the wrong word form and write the correct form next to the story.

Example: Please give me two scoop of ice cream. scoops

Every day the girl and boy at East ride bus to school. They bring pencil and book with them in their bag. One day the teacher said, "Bring thing to show all your friend." The teacher didn't say how big or small they should be, or if they could be alive.

So Alex brought his two pony. Some of the child gave them carrot. Ling brought her bee. She had hundred at home but only took fifty to school.

Beth brought her bunny. She had five of them and she let some of her classmate pet them. They were soft and furry. Jeff brought his three pig, two baby and an adult. They made so much noise that class were cancelled.

Tracy brought her family's monkey. They made everyone laugh because they were so silly when they ate two of their lunch.

All day the children, the teacher and their family were glad they had a good time. 